\title{
CMR to stratify post-TAVR paravalvular leak in patients with suboptimal echocardiography
}

\author{
Gregory Hartlage*, Salim Hayek, Vasilis Babaliaros, Patricia Keegan, Vinod Thourani, Stamatios Lerakis \\ From 17th Annual SCMR Scientific Sessions \\ New Orleans, LA, USA. 16-19 January 2014
}

\section{Background}

Despite extensive pre-procedure evaluation, greater than mild paravalvular leak (PVL) occurs in over $10 \%$ of patients undergoing transcatheter aortic valve replacement (TAVR) and is associated with worse outcomes. Echocardiography, the standard method of imaging PVL, often has limited utility due to frequently multiple eccentric regurgitant jets. Acoustic shadowing from the valve stent and native aortic valve calcification may lead to further underestimation of PVL. Cardiovascular magnetic resonance (CMR) is considered the gold standard for quantification of valvular regurgitation. We evaluated the utility of CMR to grade PVL severity and predict outcomes in patients with suboptimal echocardiography.

\section{Methods}

Seventeen non-operative post-TAVR patients (NYHA class III-IV; age $84 \pm 5$ yrs) underwent CMR due to PVL and symptoms out of proportion to echocardiographic findings or suboptimal echocardiographic study. CMR was performed on a Siemens Avanto $1.5 \mathrm{~T}$ with velocity phase imaging in the ascending aorta for flow quantification. CMR PVL severity was graded by regurgitant fraction (RF; mild $\leq 20 \%$, moderate $21-39 \%$, severe $\geq 40 \%$ ). Short- and intermediate-term follow-up was conducted after CMR. Patients were followed-up for symptoms and a composite outcome of repeat invasive therapy, heart failure hospitalization, or death.

\section{Results}

CMR was performed as early as 2 days and as late as 35 months post-TAVR in both the inpatient $(\mathrm{n}=9)$ and outpatient $(\mathrm{n}=8)$ settings. PVL grading was mild in 11 , moderate in 3, and severe in 3 patients. Compared to echocardiography, PVL severity was reclassified in $47 \%$
(5 upgraded to moderate or severe; 3 downgraded to mild). CMR findings guided further management in $71 \%$ (medical therapy including diuresis in 8 with mild or moderate PVL; invasive therapy including vascular plug closure or valve in valve deployment in 4 with moderate or severe PVL). At short-term follow-up (mean $1.7 \pm 1.4$ months), 76\% had NYHA class improvement. At intermediate-term follow-up (mean $11.6 \pm 1.0$ months), $65 \%$ had persistent improvement in NYHA class (Table 1). At one year, $47 \%(n=8)$ met the composite outcome. Outcome free survival was significantly better with $\leq$ mild PVL compared to > mild PVL (73\% vs $17 \%$; $\mathrm{p}<$ 0.05). The mean RF was larger in those reaching the composite outcome compared to those not $(24 \pm 19 \%$ vs $11 \pm 8 \%)$, with a trend towards significance $(\mathrm{p}=0.08$; Table 2). Patients undergoing repeat CMR after invasive PVL therapy $(\mathrm{n}=3)$ demonstrated a reduction in mean RF from $43 \%$ to $12 \%$.

\section{Conclusions}

CMR stratifies PVL severity in symptomatic patients with suboptimal echocardiography or discrepant results. CMR is

Table 1 CMR clinical utility and follow-up symptoms.

\begin{tabular}{ccc}
\hline & Category & Result \\
\hline CMR clinical utility & PVL grading reclassification & $47 \%(18 / 17)$ \\
& Guided further management & $71 \%(12 / 17)$ \\
Follow-up symptoms & Short-term ( $\leq 3$ months) & $76 \%(13 / 17)$ \\
& NYHA class improvement to & \\
& I or II & \\
& Intermediate-term ( 1 year) & $65 \%(11 / 17)$ \\
& Persistent NYHA class & \\
& improvement & \\
\hline
\end{tabular}

$\mathrm{CMR}=$ cardiovascular magnetic resonance; $\mathrm{PVL}=$ paravalvular leak; $\mathrm{NYHA}=$ New York Heart Association. 
Table 2 CMR PVL grading and prognosis.

\begin{tabular}{|c|c|c|c|}
\hline & Category & Result & Significance \\
\hline \multirow[t]{4}{*}{ Prognosis } & $\leq$ Mild PVL & $\begin{array}{c}73 \% \text { outcome* free } \\
\text { survival }\end{array}$ & $p<0.05$ \\
\hline & $>$ Mild PVL & $\begin{array}{c}17 \% \text { outcome* free } \\
\text { survival }\end{array}$ & \\
\hline & $\begin{array}{l}\text { - Composite } \\
\text { outcome }^{*}\end{array}$ & Mean RF $11 \pm 8 \%$ & $p=0.08$ \\
\hline & $\begin{array}{l}\text { + Composite } \\
\text { outcome* }^{*}\end{array}$ & Mean RF $24 \pm 19 \%$ & \\
\hline
\end{tabular}

$\mathrm{PVL}=$ paravalvular leak; $\mathrm{RF}=$ regurgitant fraction; ${ }^{*}$ Composite outcome $=$ repeat invasive therapy, heart failure hospitalization, or death within a year of CMR.

useful in guidance of specific post procedure therapy and has prognostic importance, with greater than mild PVL (RF $>20 \%$ ) associated significantly with worse outcomes.

\section{Funding}

None.

Published: 16 January 2014

doi:10.1186/1532-429X-16-S1-0102

Cite this article as: Hartlage et al:: CMR to stratify post-TAVR

paravalvular leak in patients with suboptimal echocardiography. Journal of Cardiovascular Magnetic Resonance 2014 16(Suppl 1):0102.

Submit your next manuscript to BioMed Central and take full advantage of:

- Convenient online submission

- Thorough peer review

- No space constraints or color figure charges

- Immediate publication on acceptance

- Inclusion in PubMed, CAS, Scopus and Google Scholar

- Research which is freely available for redistribution

Submit your manuscript at www.biomedcentral.com/submit 